\title{
Mechanistic insights of anionic ligand exchange and fullerene reduction with magnesium(I) compounds ${ }^{\dagger}$
}

Samuel R. Lawrence, David B. Cordes, Alexandra M. Z. Slawin, Andreas Stasch*

EaStCHEM School of Chemistry, University of St Andrews, North Haugh, St Andrews, KY16 9ST, United Kingdom.E-mail:as411@st-andrews.ac.uk.

$\dagger$ Electronic supplementary information (ESI) available: Experimental, spectroscopic, and crystallographic details (PDF); CCDC 1914904. See DOI: 10.1039/...

Ligand exchange reactions between combinations of the complexes $\left[\left\{\left({ }^{\mathrm{Ar}} \text { nacnac }\right) \mathrm{Mg}\right\}_{2}\right]$, where $\mathrm{Ar}=$ 2,6- $i \mathrm{Pr}_{2} \mathrm{C}_{6} \mathrm{H}_{3}$ (Dip), 2,6- $\mathrm{Et}_{2} \mathrm{C}_{6} \mathrm{H}_{3}$ (Dep), 2,4,6- $\mathrm{Me}_{4} \mathrm{C}_{6} \mathrm{H}_{2}$ (Mes), and 2,6- $\mathrm{Me}_{2} \mathrm{C}_{6} \mathrm{H}_{3} \quad(\mathrm{Xyl})$, $\left[\left(\left\{\mathrm{Ph}_{2} \mathrm{P}(\mathrm{NDip})_{2}\right\} \mathrm{Mg}\right)_{2}\right],\left[\left({ }^{\mathrm{Ar}}\right.\right.$ nacnac $\left.) \mathrm{Li}\right]$, where $\mathrm{Ar}=\mathrm{Mes}$ or $\mathrm{Xyl}$, and $\left[\left\{\mathrm{Ph}_{2} \mathrm{P}(\mathrm{NDip})_{2}\right\} \mathrm{Li}\right]$ were studied in deuterated aromatic and aliphatic solvents, and tetrahydrofuran. The reactions afforded product mixtures with asymmetrically substituted dimagnesium(I) complexes $\left[\left({ }^{\mathrm{Ar}}\right.\right.$ nacnac $) \mathrm{MgMg}\left({ }^{\mathrm{Ar}}\right.$ nacnac $\left.)\right]$, where $\mathrm{Ar}, \quad \mathrm{Ar}^{\prime}=\mathrm{Dip}, \mathrm{Dep}, \mathrm{Mes}, \mathrm{Xyl}$ and $\left[\left\{\mathrm{Ph}_{2} \mathrm{P}(\mathrm{NDip})_{2}\right\} \mathrm{MgMg}\left({ }^{\mathrm{Ar}}\right.\right.$ nacnac $\left.)\right]$, where $\mathrm{Ar}=\mathrm{Mes}$ or $\mathrm{Xyl}$, and suggest that the exchange of anionic ligands on the $\mathrm{Mg}_{2}{ }^{2+}$ ion proceeds via an associative mechanism and is strongly dependent on ligand sterics and ligand shape, and can be very rapid. The activation reaction of fullerene $\mathrm{C}_{60}$ by dimagnesium(I) complexes $\left[\left\{\left({ }^{\mathrm{Ar}} \text { nacnac }\right) \mathrm{Mg}\right\}_{2}\right]$ and $\left[\left(\left\{\mathrm{Ph}_{2} \mathrm{P}(\mathrm{NDip})_{2}\right\} \mathrm{Mg}\right)_{2}\right]$ to fulleride complexes is similarly dependent on ligand sterics and ligand shape, but likely does not involve direct coordination of the fullerene to the $\mathrm{Mg}$ centre in dimagnesium(I) compounds prior to its reduction. The new $\mathrm{C}_{60}{ }^{6-}$ fulleride complex $\left[\left(\left\{\mathrm{Ph}_{2} \mathrm{P}(\mathrm{NDip})_{2}\right\} \mathrm{Mg}\right)_{6} \mathrm{C}_{60}\right]$ was prepared, and spectroscopically and structurally characterised. 


\section{Introduction}

Stable coordination complexes of the highly reducing $\mathrm{Mg}_{2}{ }^{2+}$ ion ${ }^{1}$ have so far been obtained with a range of suitable sterically demanding anionic ligands consisting of $\beta$-diketiminates and related ligands, e.g. complexes 1 (Figure 1 ), ${ }^{2}$ a guanidinate, ${ }^{2 \mathrm{k}}$ a diazabutadienide and related systems, ${ }^{3}$ a diiminophosphinate (2), ${ }^{4}$ and amides. ${ }^{5}$ In these, the $\mathrm{Mg}_{2}{ }^{2+}$ ion contains an $\mathrm{Mg}-\mathrm{Mg} \sigma$-bond that shows almost exclusively $s$-character ${ }^{1}$ with a rare non-nuclear attractor at the midpoint of the bond. ${ }^{6}$ The $\mathrm{Mg}-\mathrm{Mg}$ bond in these complexes is relatively long, for example ca. $2.85 \AA$ for $\mathbf{1 a}$, and can significantly lengthen upon coordination of donor molecules, ${ }^{2 \mathrm{a}, 2 \mathrm{i}, 2 \mathrm{j}}$ e.g. up to $c a .3 .20 \AA$ in the vicinal bis-(4-dimethylaminopyridine) adduct of $\mathbf{1 a} \cdot{ }^{2 \mathrm{j}}$ Coordination of some donors such as THF or dioxane has been found to be facilely reversible. On the other hand, high pressure can effect a significant shortening of the $\mathrm{Mg}-\mathrm{Mg}$ bond in the solid state ${ }^{7}$ and highlights the ease of stretching and compressing the $\mathrm{Mg}-\mathrm{Mg}$ bond. As these complexes are regularly employed as very strong reducing agents towards a range of organic, inorganic and organometallic substrates, ${ }^{1}$ understanding the coordination chemistry of $\mathrm{Mg}-\mathrm{Mg}$-bonded complexes is important for their applications.

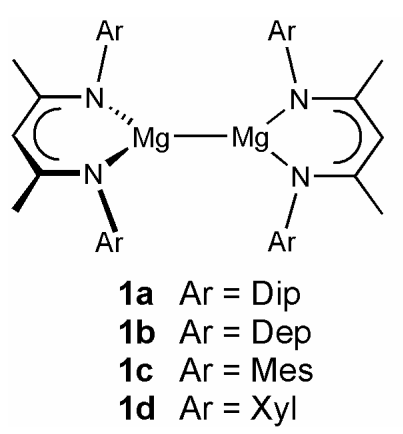

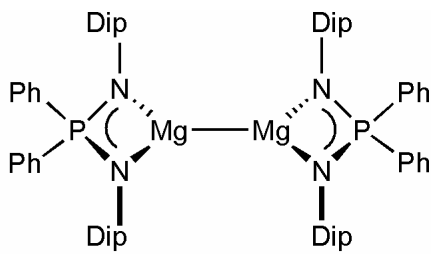

2

Fig. 1 Complexes 1 and 2. Dip = 2,6-diisoproylphenyl, Dep = 2,6-diethylphenyl, Mes = mesityl (2,4,6-trimethylphenyl), Xyl = xylyl (2,6-dimethylphenyl).

Related to $\mathrm{Mg}-\mathrm{Mg}$-bonded compounds are coordination complexes of the $\mathrm{Zn}_{2}{ }^{2+}$ ion, ${ }^{8}$ that appear to be less reducing in comparison to $\mathrm{Mg}_{2}^{2+}$ complexes and show stronger and significantly shorter metal-metal bonds (by ca. 17\%), despite having only slightly shorter $\mathrm{Zn}-\mathrm{N}$ bonds (by ca. $2.5 \%$ ) for comparable complexes. Low oxidation state zinc chemistry has also been extended to complexes of the $\mathrm{Zn}_{3}{ }^{2+}$ ion and $\mathrm{Zn}$-cluster species, for example. ${ }^{8,9}$ The coordination chemistry of $\mathrm{Zn}$-Zn-bonded complexes has so far allowed a wider variety of ligands as part of stable isolated complexes, including those of simple dicationic species $\left[(\mathrm{Do})_{3} \mathrm{Zn}-\mathrm{Zn}(\mathrm{Do})_{3}\right]^{2+}(\mathrm{Do}=$ neutral donors $) .{ }^{10}$ In the chemistry of $\mathrm{Zn}-\mathrm{Zn}$ bonded compounds, stable sources such as $\mathrm{Cp} * \mathrm{ZnZnCp} *\left(\mathrm{Cp}^{*}=\right.$ pentamethylcyclopentadienyl ${ }^{8,11}$ have been used to access new complexes with retention of the $\mathrm{Zn}-$ 
Zn bond, for example by ligand exchange reactions using proligands with protic hydrogens, ${ }^{8}$ or via metathesis reactions involving the exchange of anionic ligands. ${ }^{10 a, 12}$ In this work we report on ligand exchange reactions involving dimeric magnesium(I) compounds and considerations around ligand shapes for these reactions, and activation reactions of $\mathrm{C}_{60}$.

\section{Results and discussion}

The reactivity of dimeric magnesium(I) compounds has been found to be typically strongly dependent on ligand and substrate sterics. ${ }^{1}$ For the $\beta$-diketiminate derivatives $\mathbf{1}$, for example, it can thus significantly vary with aryl substitution. For the reduction of (organic) substrates it is believed that the molecules require coordination to one of the $\mathrm{Mg}$ centres of $\left[\left\{\left({ }^{\mathrm{Ar}} \text { nacnac }\right) \mathrm{Mg}\right\}_{2}\right] \mathbf{1}$, or at least a close approach to the $\mathrm{Mg}_{2}{ }^{2+}$ unit as a first step. This is supported by the fact that the more sterically demanding derivatives (1a) can require higher reaction temperatures or show no reaction in some cases where the less sterically demanding ones $(\mathbf{1 c}, \mathbf{d})$ rapidly react. Also, reactions in neat coordinating solvents such as THF are typically suppressed in comparison to those conducted in hydrocarbons, due to THF coordination and blocking of the $\mathrm{Mg}$ centres, despite elongated $\mathrm{Mg}-\mathrm{Mg}$ bonds in donor adduct complexes. ${ }^{2 \mathrm{j}}$ In this regard, however, it has recently been found that mono adduct formation of $\left[\left\{\left({ }^{\mathrm{Ar}} \text { nacnac }\right) \mathrm{Mg}\right\}_{2}\right] \quad \mathbf{1}$ complexes, e.g. $\quad$ as in $\left[\left({ }^{\text {Dip }}\right.\right.$ nacnac $) \operatorname{Mg}($ Do $\left.)\right\}\left\{\mathrm{Mg}\left({ }^{\text {Dip }}\right.\right.$ nacnac $\left.\left.)\right\}\right] \quad($ Do $=$ 4-dimethylaminopyridine, DMAP, or 2,3,4,5tetramethyl-imidazol-2-ylidene), can be used to lower the kinetic barrier for activation reactions and allowed the reductive trimerisation of $\mathrm{CO}$ to form magnesium deltate-complexes. ${ }^{2 \mathrm{a}}$ Also, compounds of the type $\mathrm{LMgMgL}$ have been concluded to not dissociate into $2 \mathrm{LMg}$. in solution and typically do not react via free radical mechanisms. ${ }^{1,2 f, 2 i, 2 k}$

We have recently reported the facile activation of buckminsterfullerene, $\mathrm{C}_{60}$, with $\left[\left\{\left({ }^{\mathrm{Ar}} \text { nacnac }\right) \mathrm{Mg}\right\}_{2}\right] \mathbf{1}$ affording fulleride complexes $\left[\left\{\left({ }^{\mathrm{Ar}} \text { nacnac }\right) \mathrm{Mg}\right\}_{\mathrm{n}} \mathrm{C}_{60}\right], n=6$ (3) though not for $\mathrm{Ar}=\mathrm{Dip}), 4$, and 2, that are best described as contact ion systems of $n\left[\left({ }^{\mathrm{Ar}}\right.\right.$ nacnac) $\mathrm{Mg}^{+}{ }^{+}$with $\mathrm{C}_{60}{ }^{\mathrm{n}}$ ions. ${ }^{13}$ With respect to its initial activation, the large and spherical shape of $\mathrm{C}_{60}$ makes is unlikely in our view that it can easily coordinate directly to a well protected $\mathrm{Mg}$ centre of $\mathbf{1}$ prior to reduction. As a working hypothesis we speculated that the initial approach of $\mathrm{C}_{60}$ to the $\mathrm{Mg}$ centres in $\mathbf{1}$ could be via the relatively open and unprotected $\beta$-diketiminate backbone prior to reduction. This raises questions of how facile ligand rearrangement processes in the coordination sphere of the $\mathrm{Mg}_{2}{ }^{2+}$ ion are. For example, processes such as partial dissociation and re-coordination of donor groups of ligands, and/or distortions of the coordination sphere can inevitably be linked to access of substrates to the $\mathrm{Mg}_{2}$ core prior to reduction chemistry. 
In order to study the potential rearrangement processes in $\mathrm{LMgMgL}$ complexes, we first reinvestigated ligand scrambling between different $\left[\left\{\left({ }^{\mathrm{Ar}}{ }_{\text {nacnac }}\right) \mathrm{Mg}\right\}_{2}\right] \mathbf{1}$ complexes, forming asymmetric complexes $\left[\left({ }^{\mathrm{Ar}}\right.\right.$ nacnac $) \mathrm{MgMg}\left({ }^{\mathrm{Ar}}\right.$ nacnac $\left.)\right]$ 4. Previously, the reaction of $\left[\left\{\left({ }^{\text {Dip }} \text { nacnac }\right) M g\right\}_{2}\right] \mathbf{1 a}$ and $\left[\left\{\left({ }^{\mathrm{Mes}} \text { nacnac }\right) \mathrm{Mg}\right\}_{2}\right] \mathbf{1 c}$ proceeded extremely slowly at room temperature or at $80^{\circ} \mathrm{C}$ over two weeks and with replenishment of decomposed 1c, affording predominantly $\left[\left({ }^{\text {Dip }}\right.\right.$ nacnac $) \operatorname{MgMg}\left({ }^{\mathrm{Mes}}\right.$ nacnac $\left.)\right]$ 4ac. ${ }^{2 \mathrm{f}}$ We studied the ligand influence by mixing the smaller $\beta$ diketiminate examples $\left[\left\{\left({ }^{\mathrm{Mes}} \text { nacnac }\right) \mathrm{Mg}\right\}_{2}\right] \mathbf{1 c}$ and $\left[\left\{\left({ }^{\mathrm{Xyl}} \text { nacnac }\right) \mathrm{Mg}\right\}_{2}\right] \mathbf{1 d}$ in deuterated benzene or toluene and found the completed formation of $\left[\left({ }^{\mathrm{Mes}}\right.\right.$ nacnac $) \mathrm{MgMg}\left({ }^{\mathrm{Xyl}}\right.$ nacnac $\left.)\right]$ 4cd alongside 1c and 1d after only a few minutes as judged by ${ }^{1} \mathrm{H}$ NMR spectroscopy (Figures S8-9). A statistical distribution of $c a .25 \%$ of $\mathbf{1 c}$ and $\mathbf{1 d}$, respectively, and $c a .50 \% \mathbf{4 c d}$ is formed due to the essentially identical steric and electronic profiles of the ${ }^{\text {Mes }}$ nacnac and ${ }^{\mathrm{Xyl}}$ nacnac ligands around the $\mathrm{Mg}_{2}{ }^{2+}$ unit, affording a $\Delta G^{o} \approx 0$ for this reaction. Similar scrambling reactions can be carried out at room temperature between other $\left[\left\{\left({ }^{\mathrm{Ar}} \text { nacnac }\right) \mathrm{Mg}\right\}_{2}\right] \mathbf{1}$ combinations (Scheme 1 and the ESI). Reactions involving more sterically demanding examples, e.g. 1a and $\mathbf{1 b}$, are, as expected, considerably slowed down, for example in the formation of $\left[\left({ }^{\mathrm{Dip}}\right.\right.$ nacnac $) \operatorname{MgMg}\left({ }^{\mathrm{Mes}}\right.$ nacnac $\left.)\right]$ 4ac. Complexes $\left[\left({ }^{\mathrm{Dep}}\right.\right.$ nacnac $) \operatorname{MgMg}\left({ }^{\mathrm{Mes}}\right.$ nacnac $\left.)\right]$ 4bc (Figures $\left.\mathrm{S} 4-5\right)$ and $\left[\left({ }^{\mathrm{Dep}}\right.\right.$ nacnac $) \operatorname{MgMg}\left({ }^{\mathrm{Xyl}}\right.$ nacnac $\left.)\right]$ 4bd (Figures S6-7), were formed in solution reaching a near-equilibrium mixture in under one day at room temperature.

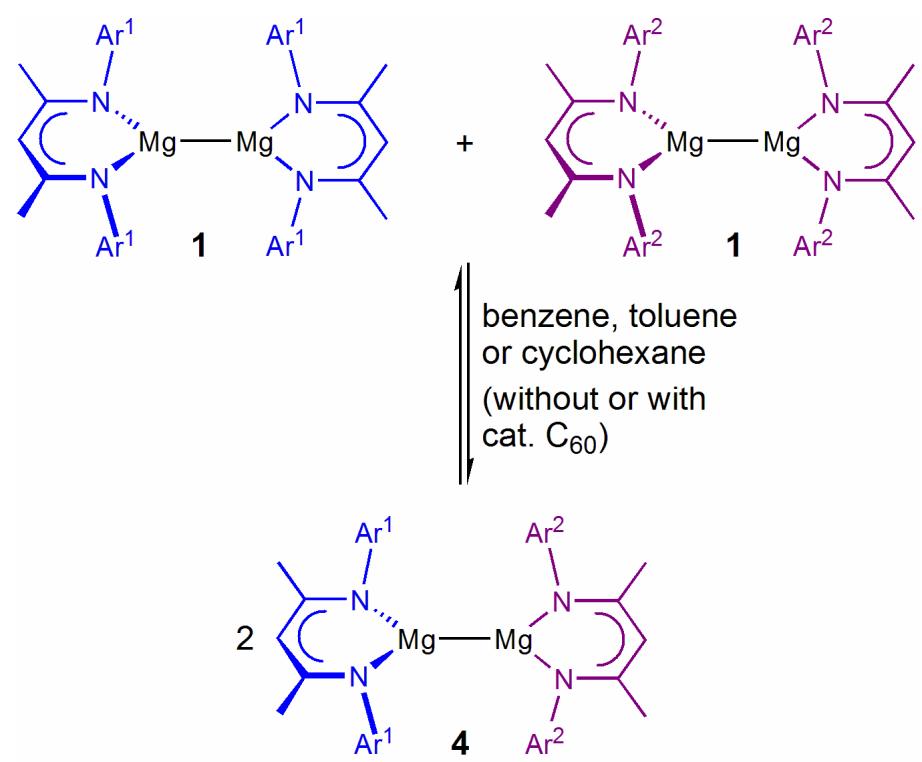

Scheme 1 Ligand scrambling reactions in complexes 1 to mixed-ligand species 4.

Arenes are often the solvent of choice for these reactions, and can be involved as neutral ligands in metal complexes, but can also form reduced, anionic ligands as part of electron-rich metal complexes. For example, it has very recently been suggested that some reactions involving 
the aluminium(I) complex [( ${ }^{\text {Dip }}$ nacnac $\left.) A l\right]$ may proceed via a reduced arene complex, ${ }^{14}$ and subsequently, structurally characterised $\mathrm{Ca} / \mathrm{Al}$ and $\mathrm{Mg}$ complexes with reduced benzene fragments have been reported, the latter is believed to be formed via radical intermediates. ${ }^{2 b, 15}$ To exclude an influence from the aromatic solvent in the reaction, e.g. via scrambling of possibly short-lived $\left[\left({ }^{\mathrm{Ar}}\right.\right.$ nacnac $) \mathrm{Mg}\left(\mathrm{C}_{6} \mathrm{H}_{5} \mathrm{R}\right) \mathrm{Mg}\left({ }^{\mathrm{Ar}}\right.$ nacnac $\left.)\right](\mathrm{R}=\mathrm{H}, \mathrm{Me})$ intermediates with reduced arene ligands, we conducted the reaction between $1 \mathbf{c}$ and $\mathbf{1 d}$ in deuterated cyclohexane. We again found the completed formation of $\mathbf{4} \mathbf{c d}$ as part of a statistical mixture at room temperature in this solvent after a few minutes, similar to the experiments in aromatic solvents (Figure S10). Conducting the reaction between $1 \mathbf{c}$ and $\mathbf{1 d}$ in neat deuterated THF, however, showed no scrambling between the molecules at room temperature even after several days (see Figure S11 for a spectrum after a few minutes), although we did find evidence for slow scrambling at $50^{\circ} \mathrm{C}$ after many days, and formation of a near-equilibrium mixture after about one month (Figure S12). Coordination of THF to complexes 1 has been found to be reversible $e^{2 j}$ and elevated temperatures are expected to support dissociation of THF ligands for entropic reasons.

We also studied the reaction of the fulleride complex $\left[\left\{\left({ }^{\mathrm{Mes}} \text { nacnac }\right) \mathrm{Mg}\right\}_{6} \mathrm{C}_{60}\right] \mathbf{3 c}$ with three equivalents of $\left[\left\{\left({ }^{\mathrm{Xyl}} \text { nacnac }\right) \mathrm{Mg}\right\}_{2}\right] \mathbf{1 d}$ in benzene at room temperature, which showed new ${ }^{1} \mathrm{H}$ NMR resonances emerging within minutes at room temperature. These support the formation of the scrambling products $\left[\left({ }^{\mathrm{Mes}}\right.\right.$ nacnac $) \mathrm{MgMg}\left({ }^{\mathrm{Xyl}}\right.$ nacnac $\left.)\right]$ 4cd, $\mathbf{1 c}$ and $\mathbf{1 d}$ in essentially statistical distribution after approximately one to two days, plus resonances we assign to a mixture of various $\left[\left\{\left({ }^{\mathrm{Mes}} \text { nacnac) } \mathrm{Mg}\right\}_{\mathrm{n}}\left\{\left({ }^{\mathrm{Xyl}} \text { nacnac }\right) \mathrm{Mg}\right\}_{6-\mathrm{n}} \mathrm{C}_{60}\right](n=0-6\right.$, but likely almost no 0 or 6$)$ complexes (Figures S14-16). Although this ligand exchange reaction is markedly slower than that between magnesium(I) species 1c and 1d, it could be possible that fulleride complexes assist in ligand scrambling reactions between different $\left[\left\{\left({ }^{\mathrm{Ar}} \text { nacnac }\right) \mathrm{Mg}\right\}_{2}\right] \mathbf{1}$ complexes on the surface of the $\mathrm{C}_{60}$ cluster. This could be of interest especially for those with sterically more demanding ligands that require long reaction times and forcing conditions accompanied by decomposition reactions. We tested the scrambling reaction of $\mathbf{1 a}$ and $\mathbf{1 c}$ with catalytic amounts of $\mathrm{C}_{60}$ both at room temperature and at elevated temperatures. Not surprisingly, we found no significant acceleration of these scrambling reactions to form $\left[\left({ }^{\text {Dip }}\right.\right.$ nacnac $) \operatorname{MgMg}\left({ }^{\mathrm{Mes}}\right.$ nacnac $\left.)\right] \mathbf{4 a c}$ when catalytic quantities of $\mathrm{C}_{60}$ were added, though noticed a significant suppression of by-product formation via the decomposition of $\left[\left({ }^{\mathrm{Ar}}\right.\right.$ nacnac $) \mathrm{MgMg}\left({ }^{\mathrm{Ar}}\right.$ nacnac) $)$ species into $\left[\left({ }^{\mathrm{Ar}} \text { nacnac }\right)_{2} \mathrm{Mg}\right]$ and $\mathrm{Mg}$ metal (see Figures S2 and S3). We also used this method successfully to generate [( ${ }^{\text {Dip }}$ nacnac) $\operatorname{MgMg}\left({ }^{\text {Dep }}\right.$ nacnac) $)$ 4ab (Figure S1) as part of a reaction mixture from dimagnesium(I) compounds 1a and $\mathbf{1 b}$ bearing the most sterically demanding aryl substituents in the series (Scheme 1). The role of the fullerene in the suppression of the decomposition is not known yet and could involve the stabilisation of reactive intermediates as part of fulleride complexes. 
Next, we studied the reactions of $2\left[\left({ }^{\mathrm{Mes}}\right.\right.$ nacnac $\left.) \mathrm{Li}\right] \mathbf{5 c}$ with $\left[\left\{\left({ }^{\mathrm{Xyl}} \text { nacnac }\right) \mathrm{Mg}\right\}_{2}\right] \mathbf{1 d}$ and $2\left[\left({ }^{\mathrm{Xyl}}\right.\right.$ nacnac $\left.) \mathrm{Li}\right] \mathbf{5 d}$ with $\left[\left\{\left({ }^{\mathrm{Mes}} \text { nacnac }\right) \mathrm{Mg}\right\}_{2}\right] \mathbf{1 c}$, respectively, scheme 2. Here, complex $\mathbf{5}$ provides a source of anionic ligands together with an inert $s$-block metal ion. An elevated temperature of $50^{\circ} \mathrm{C}$ was required for the reactions to proceed at a significant rate over several days. In both cases, the formation of $\left[\left({ }^{\mathrm{Mes}}\right.\right.$ nacnac $) \mathrm{MgMg}\left({ }^{\mathrm{Xyl}}\right.$ nacnac $\left.)\right] \mathbf{4 c d}$ was observed plus the expected by-product [( ${ }^{\mathrm{Ar}}$ nacnac $\left.) \mathrm{Li}\right] \mathbf{5}$ and some decomposition to [ $\left.\left({ }^{\mathrm{Ar}} \text { nacnac }\right)_{2} \mathrm{Mg}\right]$ complexes and $\mathrm{Mg}$ metal (Figures S17-18). With further progression, small resonances of the newly formed symmetric $\left[\left\{\left({ }^{\mathrm{Ar}} \text { nacnac }\right) \mathrm{Mg}\right\}_{2}\right]$ complexes $\mathbf{1 d}$ or $\mathbf{1 c}$ were also evident and show full ligand substitution of the starting materials. Although a strictly statistical product distribution was not reached, a $\Delta G^{o} \approx 0$ for the overall reaction can still be assumed. A significantly higher activation barrier compared to the reaction between $\mathbf{1 c}$ and $\mathbf{1 d}$ is evidenced by the higher required reaction temperatures and longer reaction times. [ $\left({ }^{\mathrm{Ar}}\right.$ nacnac) $\left.\mathrm{M}\right] \mathrm{M}=\mathrm{Na}, \mathrm{K}$ complexes were significantly less effective in these reactions due to their low solubility and the formation of metal from decomposition reactions.
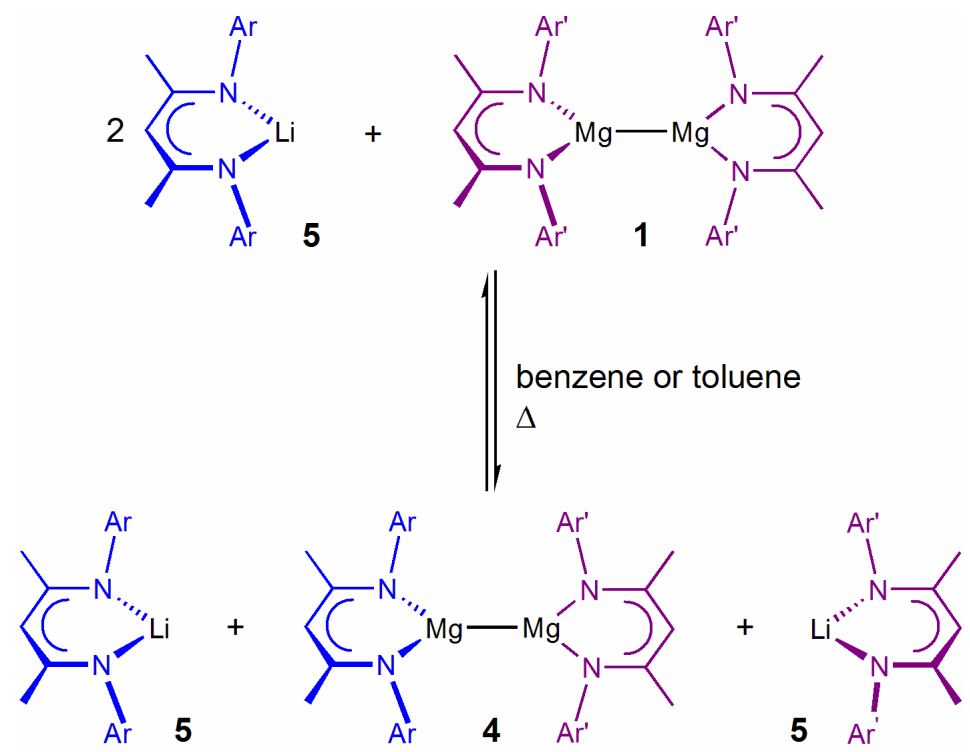

and other products, e.g. $\left[\left\{\left({ }^{\mathrm{Ar}} \text { nacnac }\right) \mathrm{Mg}\right\}_{2}\right] 1$

Scheme 2 Ligand scrambling reactions between complexes $\mathbf{1}$ and $\mathbf{5}$ to $\mathbf{4}$.

To gain further information on the influence of the ligand-type in the dimagnesium(I) compounds for these activation reactions, we compared reactions between various $\left[\left\{\left({ }^{\mathrm{Ar}} \text { nacnac }\right) \mathrm{Mg}\right\}_{2}\right]$ compounds 1 (scheme 1), to those involving the non-diketiminate derivative $\left[\left(\left\{\mathrm{Ph}_{2} \mathrm{P}(\mathrm{NDip})_{2}\right\} \mathrm{Mg}\right)_{2}\right] 2 .{ }^{4}$ The overall size of the diiminophosphinate ligand in the latter has previously been suggested to be less than that of the ${ }^{\text {Dip }}$ nacnac-ligand, approximately the same as the ${ }^{\text {Mes }}$ nacnac-ligand. ${ }^{4}$ It forms a four-membered chelating ring system with magnesium (Figure 1), and contains a very different and sterically more demanding profile in its backbone region. The scrambling reaction of $\left[\left(\left\{\mathrm{Ph}_{2} \mathrm{P}(\mathrm{NDip})_{2}\right\} \mathrm{Mg}\right)_{2}\right] \mathbf{2}$ with $\left[\left\{\left({ }^{\mathrm{Mes}} \text { nacnac }\right) \mathrm{Mg}\right\}_{2}\right] \mathbf{1 c}$ in deuterated benzene 
at room temperature proceeded very slowly and afforded resonances for $\left[\left\{\mathrm{Ph}_{2} \mathrm{P}(\mathrm{NDip})_{2}\right\} \mathrm{MgMg}\left({ }^{\mathrm{Mes}}\right.\right.$ nacnac) $] 7 \mathrm{c}$ as part of the expected product mixture (Figures S19-22). An approximate statistical distribution of $\left\{\mathrm{Ph}_{2} \mathrm{P}(\mathrm{NDip})_{2}\right\}$ and $\left({ }^{\mathrm{Mes}}\right.$ nacnac) ligands in the products supports an overall energy neutral reaction for this system. The reaction required approximately ten days and is thus significantly slower than the formation of $\mathbf{4 b c}$ from $\mathbf{1 b}$ and $\mathbf{1 c}$ which took less than one day.

We also tested the reaction of two equivalents of [ $\left({ }^{\mathrm{Ar}}\right.$ nacnac $\left.) \mathrm{Li}\right], \mathrm{Ar}=\mathrm{Mes} \mathbf{5 c}, \mathrm{Xyl} \mathbf{5 d}$, with $\left[\left(\left\{\mathrm{Ph}_{2} \mathrm{P}(\mathrm{NDip})_{2}\right\} \mathrm{Mg}\right)_{2}\right] 2$ and found that, at $50-60^{\circ} \mathrm{C}$ over several weeks, slow substitution of a $\left\{\mathrm{Ph}_{2} \mathrm{P}(\mathrm{NDip})_{2}\right\}$ ligand to form $\left[\left\{\mathrm{Ph}_{2} \mathrm{P}(\mathrm{NDip})_{2}\right\} \mathrm{Li}\right] \quad \mathbf{6}\left({ }^{31} \mathrm{P}\left\{{ }^{1} \mathrm{H}\right\} \mathrm{NMR}: \quad-6.7 \mathrm{ppm}\right){ }^{16}$ and $\left[\left\{\mathrm{Ph}_{2} \mathrm{P}(\mathrm{NDip})_{2}\right\} \mathrm{MgMg}\left({ }^{\mathrm{Ar}}\right.\right.$ nacnac $\left.)\right]$, Ar = Mes 7c, Xyl 7d $\left({ }^{31} \mathrm{P}\left\{{ }^{1} \mathrm{H}\right\} \mathrm{NMR}:\right.$ 5.8-5.9 ppm $)$ was achieved based on NMR spectroscopy (Scheme 3), although at a severely suppressed rate compared to those of the related $\beta$-diketiminate reactions in Scheme 2 (Figures S27-36). The reaction is accompanied by some decomposition reactions due to the long reaction times at elevated temperature. In contrast, the reaction of $\left[\left\{\mathrm{Ph}_{2} \mathrm{P}(\mathrm{NDip})_{2}\right\} \mathrm{Li}\right] \mathbf{6}$ with $\left[\left\{\left({ }^{\mathrm{Mes}}{ }_{\text {nacnac }}\right) \mathrm{Mg}\right\}_{2}\right]$ 1c proceeded significantly faster at $50^{\circ} \mathrm{C}$ within a few days and at an approximately comparable rate to that of $\left[\left({ }^{\mathrm{Xyl}}\right.\right.$ nacnac $\left.) \mathrm{Li}\right] \mathbf{5 d}$ with $\left[\left\{\left({ }^{\mathrm{Mes}} \text { nacnac }\right) \mathrm{Mg}\right\}_{2}\right] \mathbf{1 c}$ indicating that nucleophilic attack on a $\beta$ diketiminate-coordinated $\mathrm{Mg}_{2}{ }^{2+}$ ion is more facile than that on the diiminophosphinate-coordinated one (Scheme 3) with comparable overall size (Figures S23-26). Although $\Delta G^{o}$ may deviate from zero for this system, we propose that nucleophilic attack of $\left[\left({ }^{\mathrm{Mes}}\right.\right.$ nacnac $\left.) \mathrm{Li}\right] \mathbf{5 c}$ on $\left[\left(\left\{\mathrm{Ph}_{2} \mathrm{P}(\mathrm{NDip})_{2}\right\} \mathrm{Mg}\right)_{2}\right] \mathbf{2}$ is kinetically more hindered (higher $\left.\Delta G^{*}\right)$ and that the slow rate of reaction is not caused by an overall thermodynamic penalty for this reaction path. This kinetic hindrance is likely due because the $\left\{\mathrm{Ph}_{2} \mathrm{P}(\mathrm{NDip})_{2}\right\}$ ligand shows a smaller chelating ring size with small $(\mathrm{Ar}) \mathrm{N} \cdots \mathrm{N}(\mathrm{Ar})$ ligand "bite", a higher steric demand near the Mg centre (Dip groups) and a more protected backbone region compared to the ( ${ }^{\mathrm{Mes}}$ nacnac) ligand, despite an overall comparable size for the two ligands. 

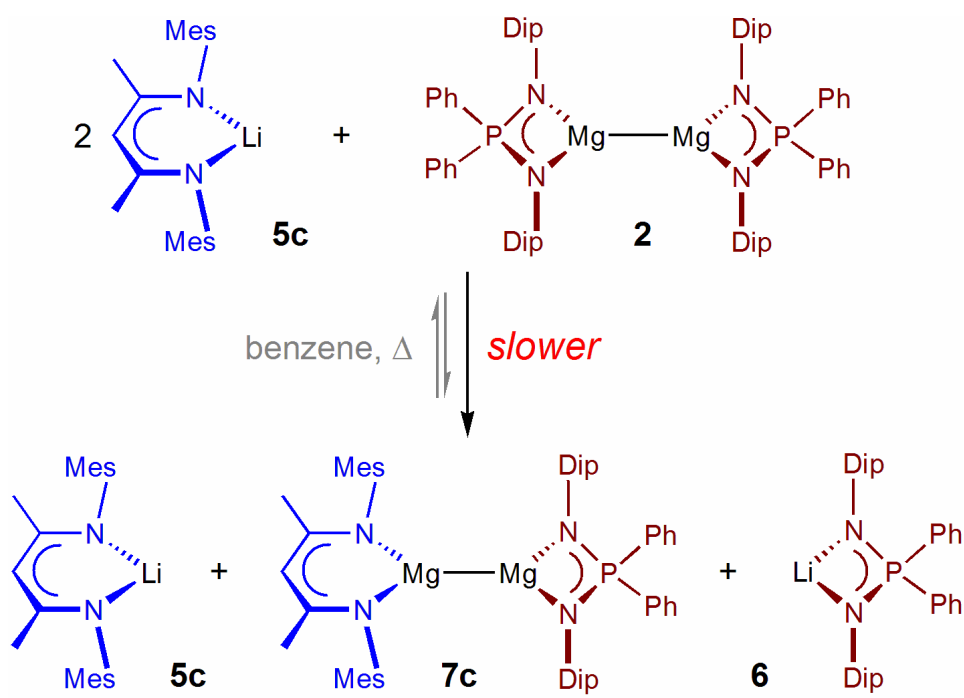

and other products

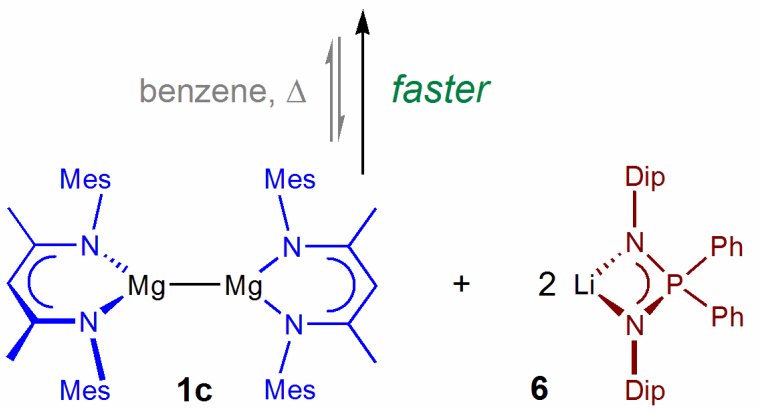

Scheme 3 Ligand scrambling reactions between complexes 2 and $\mathbf{5 c}$, and $\mathbf{1 c}$ and $\mathbf{6}$.

These series of ligand scrambling experiments suggest that the reactions between dimeric magnesium(I) complexes are exchange reactions of anionic ligands on the $\mathrm{Mg}_{2}{ }^{2+}$ ion via an associative mechanism ("nucleophilic substitution") and does not involve breaking of the $\mathrm{Mg}-\mathrm{Mg}$ bond, the latter having already been suggested previously. ${ }^{2 \mathrm{f}}$ Flexible ionic metal-ligand interactions with typically fast ligand exchange rates ${ }^{17}$ are the norm for ionic s-block metal cations and this also extends to the $\mathrm{Mg}_{2}{ }^{2+}$ ion. Nucleophilic attack on a $\beta$-diketiminate-coordinated $\mathrm{Mg}$ centre is more facile than on a comparably sized diiminophosphinate-coordinated $\mathrm{Mg}$ centre likely due to the different ligand shape with more open backbone fragment of the former. In this respect, the nucleophilic $\gamma-\mathrm{CH}$ fragment of the $\beta$-diketiminate ligands can furthermore act as another coordination site as demonstrated in the molecular structure of a crowded heteroleptic $\left({ }^{\mathrm{Mes}}\right.$ nacnac)Mg-complex, $\left[\left\{\left\{\left({ }^{\mathrm{Mes}} \text { nacnac }\right) \mathrm{Mg}\right\}_{2}\left\{(\mathrm{NCPh})_{2}\right\}\right\}_{2}\right]$, where two $\mathrm{Mg}$ are $N, N^{\prime}$-chelated by one ${ }^{\text {Mes }}$ nacnac-ligand and show a further $\kappa^{1}-\mathrm{C}$ coordination to the $\gamma-\mathrm{CH}$ fragment of a second ${ }^{\text {Mes }}$ nacnac-ligand. ${ }^{18}$ Such a coordination interaction may be involved in an associative intermediate in the anionic ligand exchange and a similar interaction is not possible for the diiminophosphinate derivative 2. The nucleophilic character of this $\gamma-\mathrm{CH}$ fragment in $\left[\left\{\left({ }^{\mathrm{Ar}} \text { nacnac }\right) \mathrm{Mg}\right\}_{2}\right] \mathbf{1}$ is also demonstrated by the reaction of $\mathbf{1}$ with diphenylketene which converts their $\beta$-diketiminate ligands 
via a nucleophilic $\gamma-\mathrm{CH}$ "attack" on the diphenylketene carbonyl centre to form $\mathrm{Mg}-\mathrm{Mg}$ bonded complexes with new tripodal ligands in high yields, leaving the $\mathrm{Mg}-\mathrm{Mg}$ unit surprisingly unaffected. $^{2 \mathrm{~g}}$

To gain possible insight on the influence of the ligand shape of dimagnesium(I) complexes in reduction reactions; i.e. if the unique shape of $\beta$-diketiminate ligands in $\left[\left\{\left({ }^{\mathrm{Ar}} \text { nacnac }\right) \mathrm{Mg}\right\}_{2}\right] \mathbf{1}$ with its open backbone geometry may similarly facilitate reactions, we tested reactions of three equivalents of $\left[\left(\left\{\mathrm{Ph}_{2} \mathrm{P}(\mathrm{NDip})_{2}\right\} \mathrm{Mg}\right)_{2}\right] 2$ with $\mathrm{C}_{60}$ in deuterated aromatic solvents at room temperature for comparison. These reactions do proceed, although significantly more slowly than those of the $\beta$-diketiminate derivatives $\mathbf{1}$, and eventually form the fulleride complex $\left[\left(\left\{\mathrm{Ph}_{2} \mathrm{P}(\mathrm{NDip})_{2}\right\} \mathrm{Mg}\right)_{6} \mathrm{C}_{60}\right] \mathbf{8}$, with full conversion of $\mathbf{2}$ only after approximately 2-3 weeks in benzene or six days in toluene (Scheme 4). As with the formation of complexes $\left[\left\{\left({ }^{A r} \text { nacnac }\right) M g\right\}_{6} \mathrm{C}_{60}\right]$ 3b-d, this solvent dependence is believed to be due to the lower solubility of $\mathrm{C}_{60}$ in benzene. ${ }^{13}$

3

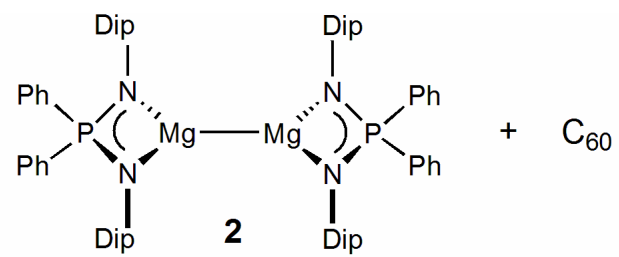

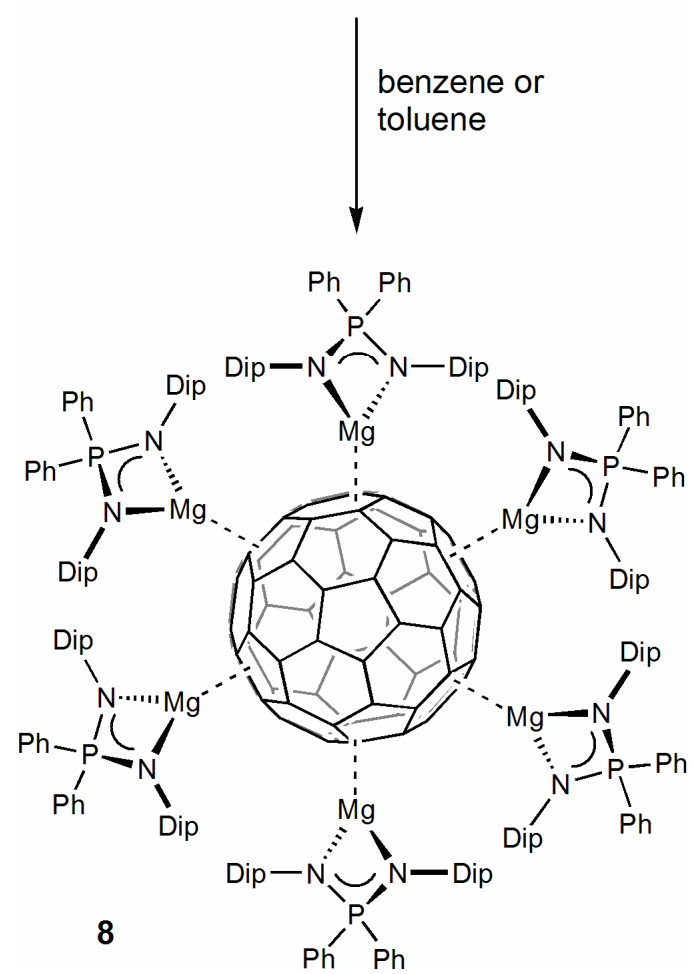

Scheme 4 Synthesis of complex 8. 
The complex $\left[\left(\left\{\mathrm{Ph}_{2} \mathrm{P}(\mathrm{NDip})_{2}\right\} \mathrm{Mg}\right)_{6} \mathrm{C}_{60}\right] \cdot 4 \mathrm{C}_{5} \mathrm{H}_{12} \mathbf{8}^{\prime}$ could be structurally characterised (see Figure 2) and crystallised from $n$-pentane with one sixth of the molecule in the asymmetric unit in the trigonal crystal system showing well-ordered $\left[\left\{\mathrm{Ph}_{2} \mathrm{P}(\mathrm{NDip})_{2}\right\} \mathrm{Mg}\right]^{+}$units and a severely disordered $\mathrm{C}_{60}{ }^{6-}$ framework (Figure 2). In the molecular structure of $\mathbf{8}^{\prime}$, six $\left[\left\{\mathrm{Ph}_{2} \mathrm{P}(\mathrm{NDip})_{2}\right\} \mathrm{Mg}\right]^{+}$ cations sit comfortably around the $\mathrm{C}_{60}{ }^{6-}$ framework in an approximately octahedral manner and thus the overall diiminophosphinate ligand size is broadly comparable to that of the smaller $\beta$ diketiminate examples (e.g. 3c,d with $\mathrm{Ar}=\mathrm{Mes}, \mathrm{Xyl})^{13}$ when the different ligand shape and chelating ring system are disregarded. For comparison, complex $\mathbf{3 b}(\mathrm{Ar}=\mathrm{Dep})$ is sterically very crowded around the fulleride fragment and not stable in solution. Complex $\mathbf{3 a}(\mathrm{Ar}=\mathrm{Dip})$ could not be formed due to the large size of the ${ }^{\text {Dip }}$ nacnac-ligand and $\left[\left\{\left({ }^{\text {Dip }} \text { nacnac }\right) M g\right\}_{4} \mathrm{C}_{60}\right]$ formed instead. Complex 8 shows resonances in ${ }^{1} \mathrm{H}$ and ${ }^{13} \mathrm{C}\left\{{ }^{1} \mathrm{H}\right\}$ NMR spectra for one ligand environment though signals for isopropyl methyl groups are extremely broadened at room temperature (Figures S37-39). These gradually sharpen with increased temperature and show one relatively sharp doublet at $100^{\circ} \mathrm{C}$ in the ${ }^{1} \mathrm{H}$ NMR spectrum (Figures S40-41). As expected, one sharp ${ }^{13} \mathrm{C}\left\{{ }^{1} \mathrm{H}\right\}$ NMR resonance for the $\mathrm{C}_{60}{ }^{6-}$ framework is observed at $154.9 \mathrm{ppm}$ (benzene- $d_{6}$ ) or $155.3 \mathrm{ppm}$ (toluene- $d_{8}$ ) at room temperature. Note that these chemical shifts are slightly closer to $\beta$-diketiminate $\mathrm{C}_{60}{ }^{2-}$ complexes (ca. $156 \mathrm{ppm}$ ) than $\mathrm{C}_{60}{ }^{6-}$ complexes 3 (ca. $\left.153 \mathrm{ppm}\right){ }^{13}$

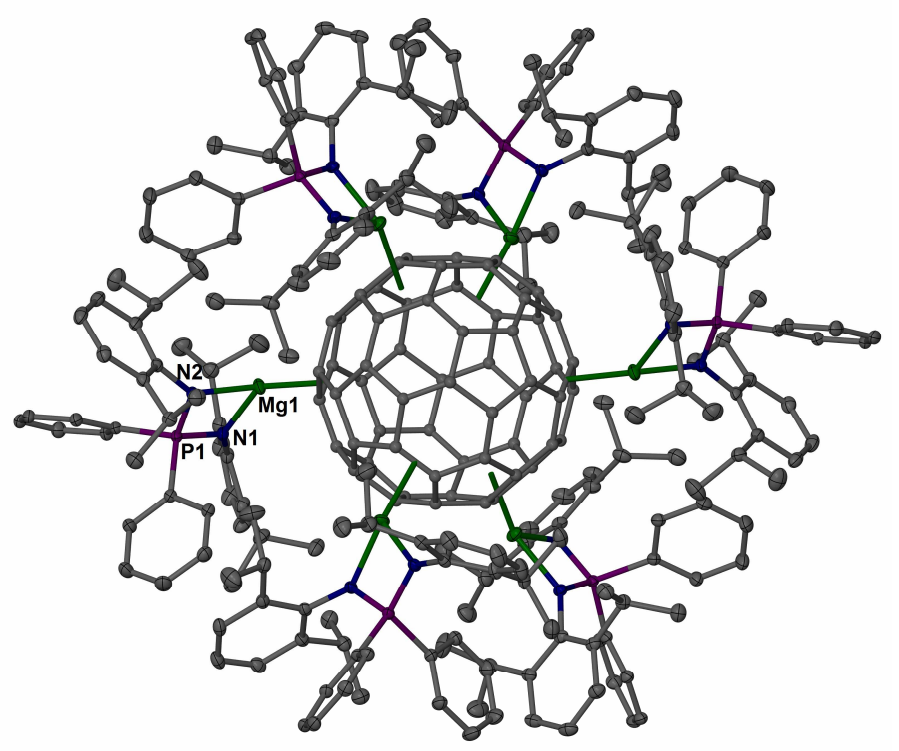

Fig. 2 Molecular structure of $\mathbf{8}^{\prime}$ (25\% thermal ellipsoids); $\mathrm{C}_{60}$ shown as spheres. Hydrogen atoms not shown. Only one of twelve sets of disordered $\mathrm{C}_{60}$ positions is shown. Due to the disorder of the $\mathrm{C}_{60}$ unit, no $\mathrm{Mg}-\mathrm{C}$ or $\mathrm{C}-\mathrm{C}$ interactions are given. Selected bond lengths and angles: $\mathrm{Mg}(1)-\mathrm{N}(1)$ 2.0271(19), $\mathrm{Mg}(1)-\mathrm{N}(2)$ 2.0197(19), $\mathrm{P}(1)-\mathrm{N}(1)$ 1.6166(18), $\mathrm{P}(1)-\mathrm{N}(2)$ 1.6236(17), $\mathrm{P}(1)-\mathrm{C}(13)$ 1.810(2), $\mathrm{P}(1)-\mathrm{C}(19)$ 1.819(2), $\mathrm{P}(1) \cdots \mathrm{Mg}(1)$ 2.6391(9); $\mathrm{N}(2)-\mathrm{Mg}(1)-\mathrm{N}(1)$ 75.30(7), N(1)-P(1)-N(2) 99.44(9), C(13)-P(1)-C(19) 101.87(10). 
That steric effects are important in the activation of $\mathrm{C}_{60}$ by dimagnesium(I) compounds was demonstrated by the severely suppressed rate of formation for the diiminophosphinate species $\left[\left(\left\{\mathrm{Ph}_{2} \mathrm{P}(\mathrm{NDip})_{2}\right\} \mathrm{Mg}\right)_{6} \mathrm{C}_{60}\right] \mathbf{8}$ in comparison to related $\beta$-diketiminate derivatives, and by a competition reaction of a freshly prepared mixture of three equivalents of $\left[\left\{\left({ }^{\text {Dip }} \text { nacnac }\right) \mathrm{Mg}\right\}_{2}\right] \mathbf{1 a}$ and three equivalents of $\left[\left\{\left({ }^{\mathrm{Mes}} \text { nacnac }\right) \mathrm{Mg}\right\}_{2}\right] \mathbf{1 c}$ with one equivalent of $\mathrm{C}_{60}$ in an arene solvent. Here, only resonances for the fulleride complex $\left[\left\{\left({ }^{\mathrm{Mes}} \text { nacnac }\right) \mathrm{Mg}\right\}_{6} \mathrm{C}_{60}\right] \mathbf{3 c}$ were observed soon after addition of the fullerene. ${ }^{13}$ For reactions in coordinating solvents, we found that the facile and rapid ligand exchange reaction between 1c and 1d to 4cd observed in hydrocarbon solvents is completely suppressed in neat THF at room temperature, vide supra, due to blocking of the Mg centres from THF coordination. We previously noted that the addition of THF to an arene solution of $\left[\left\{\left({ }^{\mathrm{Mes}} \text { nacnac }\right) \mathrm{Mg}\right\}_{6} \mathrm{C}_{60}\right] \mathbf{3 c}$ leads to the precipitation of insoluble, likely ionic fulleride complexes. ${ }^{13}$ For context, previously the reaction of $\left[\left\{\left({ }^{\mathrm{Mes}}{ }_{\text {nacnac }}\right) \mathrm{Mg}\right\}_{6} \mathrm{C}_{60}\right] \mathbf{3 c}$ with six equivalents of $\left[\left({ }^{\mathrm{Xyl}}\right.\right.$ nacnac $\left.) \mathrm{Li}\right]$ very rapidly formed the magnesium(II) complex $\left[\left({ }^{\mathrm{Mes}}\right.\right.$ nacnac $) \mathrm{Mg}\left({ }^{\mathrm{Xyl}}\right.$ nacnac $\left.)\right]$ and supports the very facile breaking of the ionic $\left\{\left({ }^{\mathrm{Mes}} \text { nacnac }\right) \mathrm{Mg}\right\}^{+} \cdots \mathrm{C}_{60}{ }^{6-}$ coordination bonds. ${ }^{13}$ When we tested the reaction of three equivalents of $\left.\left[\left\{{ }^{\mathrm{Mes}} \text { nacnac }\right) \mathrm{Mg}\right\}_{2}\right] \mathbf{1 c}$ with $\mathrm{C}_{60}$ in deuterated THF, however, we found that a reaction did occur to an insoluble precipitate within several hours to one day. This rate is not much slower than that for a reaction in benzene, and especially notable when the poor solubility of $\mathrm{C}_{60}$ in THF is considered. ${ }^{19}$ Although we were unable to identify the product composition as yet, the fact that essentially all the THF-adduct of [ $\left\{{ }^{\mathrm{Mes}}\right.$ nacnac $\left.\left.) \mathrm{Mg}\right\}_{2}\right] \mathbf{1 c}$ had reacted and that the small soluble proportion of $\mathrm{C}_{60}$ experience an excess of the magnesium(I) complex in solution during the reaction, led us to believe that a product of the $\mathrm{C}_{60}{ }^{6-}$ ion is likely. This reactivity implies that the $\mathrm{Mg}$ centres of dimagnesium(I) compounds do not require direct coordination to $\mathrm{C}_{60}$ as part of the rate-determining activation step. This may instead hint at a different mechanism as part of the initial activation, e.g. electron transfer processes involving a radical intermediate when the species are in close proximity, possibly transferred via the ligand backbone.

\section{Conclusions}

Exchange reactions of anionic ligands between magnesium(I) dimers with different supporting ligands likely occur via an associative process and are strongly dependent on sterics. These can be very rapid at room temperature as demonstrated by exchange reactions between $\left[\left\{\left({ }^{\mathrm{Mes}} \text { nacnac }\right) \mathrm{Mg}\right\}_{2}\right]$ $\mathbf{1 c}$ and $\left[\left\{\left({ }^{\mathrm{Xyl}} \text { nacnac }\right) \mathrm{Mg}\right\}_{2}\right] \mathbf{1 d}$ to form $\left[\left({ }^{\mathrm{Mes}}\right.\right.$ nacnac $) \mathrm{MgMg}\left({ }^{\mathrm{Xyl}}\right.$ nacnac $\left.)\right] \mathbf{4 c d}$. In the chemistry of $\mathrm{Zn}-$ Zn-bonded complexes, the exchange of anionic ligands as part of metathesis chemistry has been used for the synthesis of new dizinc(I) complexes. ${ }^{8,10 a, 12}$ Similarly, anionic ligands can be 
exchanged between magnesium(I) dimers and lithium complexes of suitable ligands; the latter process required more forcing reaction conditions in comparison. These reactions can be used to generate new magnesium(I) dimers bearing two different anionic ligands for example. The studies furthermore suggest that in addition to the overall ligand size, the ligand shape is important for these reactions. We suggest that the open backbone region of the $\beta$-diketiminate ligand facilitates this exchange possibly involving the "vacant coordination site" of the nucleophilic $\gamma-\mathrm{CH}$ unit of $\beta$ diketiminates. Ligand exchange reactions between different magnesium(I) dimers catalysed by $\mathrm{C}_{60}$ did not show significant acceleration though we found a significant suppression of decomposition reactions from disproportionation reactions. While anionic ligands are exchanged in the uncatalysed reactions, scrambling of $\mathrm{LMg}$ units could in addition be possible when fullerides are involved.

We also propose that the reduction of $\mathrm{C}_{60}$ with $\left[\left\{\left({ }^{\mathrm{Ar}} \text { nacnac }\right) \mathrm{Mg}\right\}_{2}\right] \mathbf{1}$ is facilitated by the unique shape of $\beta$-diketiminate ligands. In contrast, reactions of $\mathrm{C}_{60}$ with the diiminophosphinate complex $\left[\left(\left\{\mathrm{Ph}_{2} \mathrm{P}(\mathrm{NDip})_{2}\right\} \mathrm{Mg}\right)_{2}\right] 2$ with a more protected ligand backbone region are significantly slowed down, and form the expected structurally characterised fulleride complex $\left[\left(\left\{\mathrm{Ph}_{2} \mathrm{P}(\mathrm{NDip})_{2}\right\} \mathrm{Mg}\right)_{6} \mathrm{C}_{60}\right]$ 8. The fact that six cationic diiminophosphinate magnesium complex fragments arrange comfortably around the fulleride is further support that its overall size is more comparable to that of $\left[\left\{\left({ }^{\mathrm{Mes}} \text { nacnac }\right) \mathrm{Mg}\right]^{+}\right.$cation. Coordination of $\mathrm{C}_{60}$ to a $\mathrm{Mg}$ centre of a magnesium(I) dimer is likely not involved in the rate-determining activation step because a reaction between $\left[\left\{\left({ }^{\mathrm{Mes}}{ }_{\text {nacnac }}\right) \mathrm{Mg}\right\}_{2}\right] \mathbf{1 c}$, and $\mathrm{C}_{60}$ still occurs in THF at room temperature. Steric factors do play a role in the activation and a close approach of the molecules without initial $\mathrm{Mg}^{\cdots} \mathrm{C}_{60}$ coordination may be involved.

\section{Conflict of interest}

The authors declare no conflict of interest.

\section{Acknowledgements}

This work was supported by the University of St Andrews and the EPSRC (PhD studentship for SRL; EP/N509759/1). 


\section{References}

1 (a) C. Jones, Nat. Rev. Chem., 2017, 1, 0059; (b) C. Jones and A. Stasch, Top. Organomet. Chem., 2013, 45, 73-101; (c) A. Stasch and C. Jones, Dalton Trans., 2011, 40, 5659-5672.

2 (a) K. Yuvaraj, I. Douair, A. Paparo, L. Maron and C. Jones, J. Am. Chem. Soc., 2019, 141, 8764-8768; (b) T. X Gentner, B. Rösch, G. Ballmann, J. Langer, H. Elsen and S Harder, Angew. Chem. Int. Ed., 2019, 58, 607-611; (c) S. J. Bonyhady, D. Collis, N. Holzmann, A. J. Edwards, R. O. Piltz, G. Frenking, A. Stasch and C. Jones, Nat. Commun., 2018, 9, 3079; (d) J. Li, M. Luo, X. Sheng, H. Hua, W. Yao, S. A. Pullarkat, L. Xua and M. Ma, Org. Chem. Front., 2018, 5, 35383547; (e) I. Pernik, B. J. Maitland, A. Stasch and C. Jones, Can. J. Chem., 2018, 96, 513-521; (f) C. Bakewell, A. J. P. White and M. R. Crimmin, J. Am. Chem. Soc., 2016, 138, 12763-12766; (g) A. J. Boutland, I. Pernik, A. Stasch and C. Jones, Chem. Eur. J., 2015, 21, 15749-15758; (h) R. Lalrempuia, C. E. Kefalidis, S. J. Bonyhady, B. Schwarze, L. Maron, A. Stasch and C. Jones, J. Am. Chem. Soc., 2015, 137, 8944-8947; (i) S. J. Bonyhady, C. Jones, S. Nembenna, A. Stasch, A. J. Edwards and G. J. McIntyre, Chem. Eur. J., 2010, 16, 938-955; (j) S. P. Green, C. Jones and A. Stasch, Angew. Chem. Int. Ed., 2008, 47, 9079-9083; (k) S. P. Green, C. Jones and A. Stasch, Science, 2007, 318, 1754-1757.

3 (a) M. Ma, H. Wang, J. Wang, L. Shen, Y. Zhao, W.-H. Xu, B. Wu and X.-J. Yang, Dalton Trans., 2019, 48, 2295-2299; (b) Y. Liu, S. Li, X.-J. Yang, P. Yang and B. Wu, J. Am. Chem. Soc., 2009, 131, 4210-4211.

4 A. Stasch, Angew. Chem. Int. Ed., 2014, 53, 10200-10203.

5 A. J. Boutland, D. Dange, A. Stasch, L. Maron and C. Jones, Angew. Chem. Int. Ed., 2016, 55, 9239-9243.

6 (a) J. A. Platts, J. Overgaard, C. Jones, A. Stasch and B. B. Iversen, J. Phys. Chem. A, 2011, 115, 194-200; (b) J. Overgaard, C. Jones, A. Stasch and B. B. Iversen, J. Am .Chem. Soc., 2009, 131, 4208-4209.

7 L.-C. Wu, C. Jones, A. Stasch, J. A. Platts and J. Overgaard, Eur. J. Inorg. Chem., 2014, 32, $5536-5540$.

8 (a) T. Li, S. Schulz, P. W. Roesky, Chem. Soc. Rev., 2012, 41, 3759-3771; (b) E. Carmona and A. Galindo, Angew. Chem. Int. Ed., 2008, 47, 6526-6536.

9 (a) C. Bakewell, B. J. Ward, A. J. P. White and M. R. Crimmin, Chem. Sci., 2018, 9, 23482356; (a) H. Banh, K. Dilchert, C. Schulz, C. Gemel, R. W. Seidel, R. Gautier, S. Kahlal, J. Y. Saillard and R. A. Fischer, Angew. Chem. Int. Ed., 2016, 55, 3285-3289; (b) J. Hicks, E. J. Underhill, C. E. Kefalidis, L. Maron and C. Jones, Angew. Chem. Int. Ed. 2015, 54, 10000-10004. 
10 (a) H. Banh, C. Gemel, R. W. Seidel and R. A. Fischer, Chem. Commun., 2015, 51, 21702172; (b) S. Schulz, D. Schuchmann, I. Krossing, D. Himmel, D. Bläser and R. Boese, Angew. Chem., Int. Ed., 2009, 48, 5748-5751.

11 (a) A. Grirrane, I. Resa, A. Rodriguez, E. Carmona, E. Alvarez, E. Gutierrez-Puebla, A. Monge, A. Galindo, D. del Rio and R. A. Andersen, J. Am. Chem. Soc., 2007, 129, 693-703; (b) I. Resa, E. Carmona, E. Gutierrez-Puebla and A. Monge, Science, 2004, 305, 1136-1138.

12 S. Gondzik, D. Bläser, C. Wölper and S. Schulz, Chem. Eur. J., 2010, 16, 13599-13602.

13 S. R. Lawrence, C. A. Ohlin, D. B. Cordes, A. M. Z. Slawin and A. Stasch, Chem. Sci., 2019, DOI: 10.1039/C9SC03857D.

14 S. Jain and K. Vanka, Chem. Eur. J., 2017, 23, 13957-13963.

15 S. Brand, H. Elsen, J. Langer, W. Donaubauer, F. Hampel and S. Harder, Angew. Chem. Int. Ed., 2018, 57, 14169-14173.

16 A. L. Hawley and A. Stasch, Eur. J. Inorg. Chem., 2015, 258-270.

17 L. Helm and A. E. Merbach, Coord. Chem. Rev., 1991, 187, 151-181.

18 M. Ma, A. Stasch and C. Jones, Chem. Eur. J., 2012, 18, 10669-10676.

19 R. S. Ruoff, D. S. Tse, R. Malhotra and D. C. Lorents, J. Phys. Chem., 1993, 97, 33793383. 
Table of contents entry:

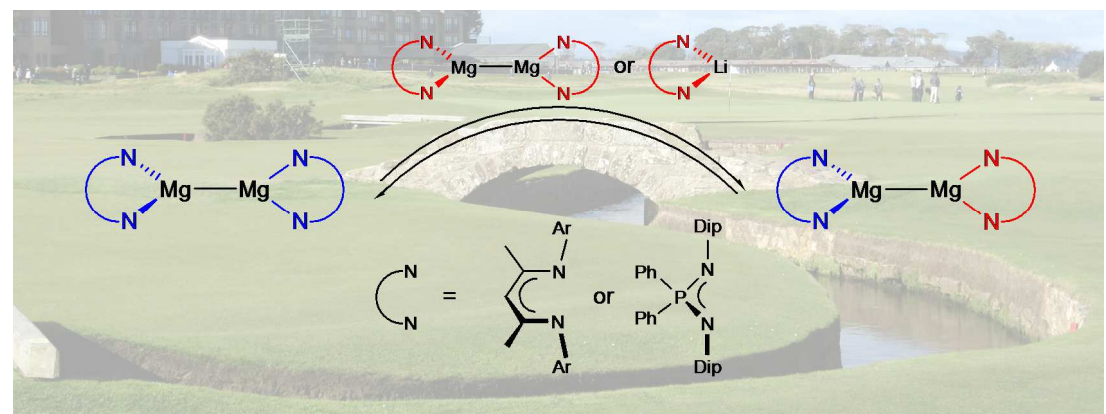

Exchange of anionic ligands on the $\mathrm{Mg}_{2}{ }^{2+}$ ion via an associative mechanism can be facile and depends on ligand sterics and shape. 